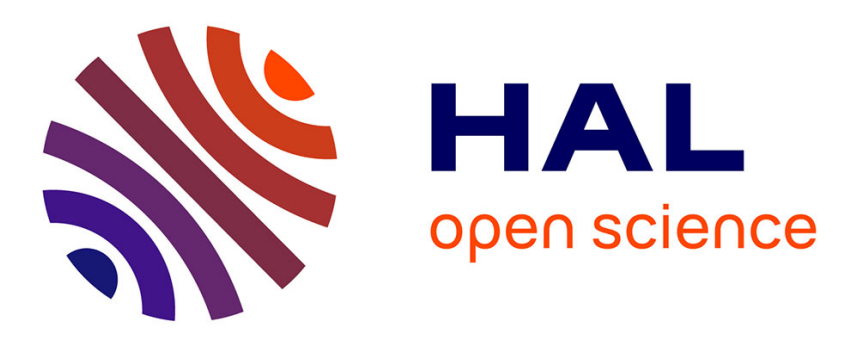

\title{
How does instant autovaporization deepen the cold press-extraction process of sunflower vegetal oil?
}

Amal Zeaiter, Colette Besombes, Larbi Rhazi, Amira Haddarah, Tayssir

Hamieh, Karim Allaf

\section{To cite this version:}

Amal Zeaiter, Colette Besombes, Larbi Rhazi, Amira Haddarah, Tayssir Hamieh, et al.. How does instant autovaporization deepen the cold press-extraction process of sunflower vegetal oil?. Journal of Food Engineering, 2019, 263, pp.70-78. 10.1016/j.jfoodeng.2019.04.024 . hal-02478421

\section{HAL Id: hal-02478421}

\section{https://hal-univ-rochelle.archives-ouvertes.fr/hal-02478421}

Submitted on 25 Oct 2021

HAL is a multi-disciplinary open access archive for the deposit and dissemination of scientific research documents, whether they are published or not. The documents may come from teaching and research institutions in France or abroad, or from public or private research centers.
L'archive ouverte pluridisciplinaire HAL, est destinée au dépôt et à la diffusion de documents scientifiques de niveau recherche, publiés ou non, émanant des établissements d'enseignement et de recherche français ou étrangers, des laboratoires publics ou privés.

\section{(ㄷ)(1) $(2$}

Distributed under a Creative Commons Attribution - NonCommerciall 4.0 International 


\title{
1 How Does Instant Autovaporization Deepen the Cold Press-Extraction Process \\ of Sunflower Vegetal Oil?
}

\author{
Amal ZEAITER ${ }^{1,2,3}$, Colette BESOMBES ${ }^{3}$, Larbi RHAZI ${ }^{4}$, Amira HADDARAH $^{1}$, Tayssir HAMIEH ${ }^{1,2}$, \\ Karim ALLAF ${ }^{3}$.
}

1. Lebanese University, Doctoral School of Science and Technology, Hadath, Beirut, Lebanon²; amal.zeaiter@etudiant.univ-Ir.fr; amirahaddara@hotmail.com.

2. Lebanese University, Faculty of Sciences, Laboratory of Materials, Catalysis, Environment and Analytical Methods (MCEMA), Hadath, Beirut, Lebanon; tayssir.hamieh@ul.edu.lb.

3. La Rochelle University, Intensification of Transfer Phenomena on Industrial EcoProcesses, Laboratory of Engineering Science for Environment LaSIE - UMR-CNRS 7356, 17042 La Rochelle, France; Phone: +33685816912, email: kallaf@univ-Ir.fr; colette.besombes@univ-Ir.fr.

\section{Abbreviation list:}

DIC: Instant Controlled Pressure-Drop

CCD: $\quad$ Central Composite Design

RSM: $\quad$ Response Surface Methodology.

K: $\quad$ Matrix permeability coefficient $\left(\mathrm{m}^{2}\right)$

v: $\quad$ Kinematic viscosity $\left(\mathrm{m}^{2} \mathrm{~s}^{-1}\right)$

A: $\quad$ Flux surface $\left(m^{2}\right)$.

Pt: $\quad$ Total pressure.

HTST: High Temperature-Short Time

DoE: Design of Experiments

Y: $\quad$ Response

$\beta_{\mathrm{i},} \beta_{\mathrm{ii}}$, and $\beta_{\mathrm{ij}}$ : Regression coefficients

$X_{i}$ : $\quad$ Independent variables

$\varepsilon: \quad$ Random error

$\mathrm{i}$ and $\mathrm{j}$ : Factor indices.

HPLC: High Performance Liquid Chromatography

RIE: $\quad$ Ratio of Improvement of oil Extraction

Ypress: $\quad$ Cold-press oil extraction yield (g Oil/g ddb).

$Y_{\text {cake: }} \quad$ Residual cake oil (g Oil/g ddb).

$Y_{\text {whole seeds: }}$ Total sunflower seed yield (g Oil/g ddb).

$\mathrm{ddb}$ : dry dry basis (mass basis of raw material devoid of water and oil).

$\mathrm{db}: \quad$ dry basis (mass basis of raw material devoid of water).

$P$ : $\quad$ Saturated dry steam pressure.

AOAC: $\quad$ AOAC International (Standards of Association of Official Analytical Chemists).

$\mathrm{t}: \quad$ Heat treatment time.

$R^{2}$ : Regression coefficient.

RM: $\quad$ Raw Material.

TMH: 2,3,5-trimethylhydroquinone. 
Sunflower oil industry is interested in both increasing yield and preserving quality of the extracted oil. The current work aimed to investigate the effect of texturing by instant controlled pressure-drop (DIC) on oil cold-press extraction. DIC texturing consists of heating at saturated dry-steam pressure $\mathrm{P}\left(200-700 \mathrm{kPa}\right.$ or $\left.110-160^{\circ} \mathrm{C}\right)$, for a short processing time $t$, followed by an instantaneous pressure-drop ( $20-40 \mathrm{~ms}$ ) towards a vacuum (3-5 kPa). This resulted in increasing oil pressing-yield up to $46 \%$ and $33 \%$, for linoleic and oleic varieties, respectively. It also increased the whole-oil availability by $11 \%$, with a conservation of the biochemical composition of both oil and residual cake. A multi-criteria optimization of the DIC operating parameters; $P$ and $t$, was performed through a 5-level Central Composite Design (CCD) and statistical analyses. This highlighted the direct significant effect of $t$ on the oil yield while greatly preserving the quality of the final products.

Keywords: Sunflower Seeds; Instant Controlled Pressure-Drop (DIC); Cold-Press Extraction; oil quality; Central Composite Design (CCD), Response Surface Methodology (RSM).

\section{Introduction}

Sunflower is a famous oleaginous plant widespread on all continents due to its hardiness and low requirements for both inputs and water (Castro and Leite, 2018). Worldwide, its cultivation is one of the largest in the world in Americas (Canada, Brazil, Argentina, USA)(Heiser, 2008), Asia (China, India, Indonesia) and Europe in particular in France (Gunstone, 2009). The sunflower seed consists of a shell and a kernel. The shell represents 70-90\% of the dry matter formed from lignin, hemicellulose, cellulose fiber and a small amount of lipids and proteins (Connor and Hall, 1997), while the kernel, with about $20 \%$ of the dry matter of the seed, is the storage place of reserve for embryonic development (Roche et al., 2004). Its lipid content is close to $44 \%$, having a distribution of the main saturated fatty acids: palmitic acid (C16: 0 ) of $5 \%-7 \%$, stearic acid (C18: 0 ) of $<10 \%$, and unsaturated: oleic acid (C18: 1) of 17\%-20\% and linoleic acid (C18: 2) of 50\%-70\% (Ayerdi Gotor et al., 2016).

Diversification of sunflower varieties results in differences in the levels of linoleic and oleic fatty acids. It generally meets the technological needs and requirements of the food and non-food industries. For the food sector, sunflower has beneficial effects on human health. It is a source of vitamin E, a dietary ingredient well-known for its anti-cholesterol properties (Pelletier et al., 1995). It is also used in margarine (Moreau et al., 2002), canning, salad dressings, table oil, and infant formula. Moreover, in the non-food sector, oleic sunflower oil is valued because of its content of fatty acids as well as the presence of minor compounds favorable to the manufacturing of pharmaceutical or cosmetic products, lubricants (Al Mahmud et al., 2013), cleaning products, solvents in the paintings, etc. It can be used for the production of both edible products and biofuel for diesel engines as a result of esterification often with the methyl ester (Rashid et al., 2008) (Del Gatto et al., 2015), (Ayerdi-Gotor et al., 200811-12).

As an edible product, and because of the negative health effects of solvent traces, it is preferable that the industrial extraction of sunflower oil is obtained by pressing. However, press-cake would generally have a high residual oil content of 15 to $20 \%$, which is too high for livestock feed or as a biomaterial (Isobe et al., 1992). This point also has a significant 
economic impact due to the price difference between the oil and the residual solid cake. Since the consumer demands to avoid the use of solvent extraction, an increase in the extraction efficiency of the press becomes an essential objective in improving the performance of the industrial process.

From fundamental and phenomenological point of view (Bouallegue et al., 2015), pressextraction is based on the gradient of total-pressure as driving force. This similar Darcysystem can be presented as following:

$$
\dot{m}_{o i l}=-\frac{K}{v} \vec{A} \cdot \overrightarrow{g r a d}\left(P_{t}\right)
$$

Where $\mathrm{K}$ is the oil-matrix permeability coefficient expressed in $\mathrm{m}^{2}, v$ the kinematic viscosity expressed in $\mathrm{m}^{2} \mathrm{~s}^{-1}, A$ the normal oil-flux surface expressed in $\mathrm{m}^{2}$, and $\mathrm{P}_{\mathrm{t}}$ the total pressure. $A$ hydrostatic liquid behavior of the material, through for example high water content, induces a more homogeneous total pressure and, then, a too weak gradient of total pressure. Hence, the use of dried seeds is an inexorable condition in press-extraction operation (Bouallegue et al., 2016). Therefore, to increase the pressed oil yield, one has to spread the pressure gradient, reduce both viscosity and product thickness. In addition, heating is well known to be capable of inducing increased yields through some thermal degradation of the cell walls. However, this operation inevitably induces a certain degradation of the main molecules and ingredients, many users recommend not to insert it. Hence, the objective of increasing the oil extraction yield must be coalesced with a perfect preservation of quality, and specialists advise against the use of heating as pretreatment and opt for a cold-press method to preserve the quality of both extracted oil and cake (Boutin and Badens, 2009).

A specific intensification of the process can be obtained by texturing by Instant Controlled Pressure-Drop (DIC), which normally increases the value of the initial permeability coefficient through higher porosity and better tortuosity of the matrix. Moreover, DIC texturing may also result in breaking the cell-walls, thus allowing the oil availability to be higher. However, once the consolidation stage of pressing is reached, porosity disappears and only some tortuosity effect and, much more, the oil availability issued from broken cellwalls persist. However, the DIC technique proposed for texturing sunflower seeds may possibly affect the functional properties of sunflower seeds, while probably preserving the quality of the oil extracted and the residual solid cake (Van, 2010).

Indeed, the challenge of using instant pressure-controlled DIC coupled with cold press to well extract the sunflower seed oil must is worth to be studied to obtain the benefits of increasing oil yields and preserving the high quality of the oil (Ixtaina et al., 2011), (Cường, 2013). Thus, the oil from DIC-assisted cold pressing extraction must be analyzed to prove that it has the same quality as conventional cold-pressed oil, in terms of biochemical composition, sensory characteristics, and color. The oil must meet to all international oil standards.

\section{Materials and methods}

\subsection{Raw materials and chemicals}

The sunflower seeds were supplied by the company "Presse de Gascogne" in Cologne (France). This company specializes in the field of organic French-origin sunflower food oil. 
Two varieties of sunflower: linoleic and oleic types were used. They were transported to the laboratory and well packaged, and stored at room temperature. The initial moisture content dry basis $(\mathrm{db})\left(\mathrm{W}_{\mathrm{i}}\right)$ was about $0.07 \pm 0.005 \mathrm{~g} \mathrm{H}_{2} \mathrm{O} / \mathrm{g} \mathrm{db}$ for the linoleic sample and $0.09 \pm$ $0.005 \mathrm{~g} \mathrm{H}_{2} \mathrm{O} / \mathrm{g} \mathrm{db}$ for the oleic sample. Our study on cold-pressing extraction has concerned the whole sunflower seeds, thus maintaining their hulls.

130 The chemicals such as $99.99 \%$ purity $n$-hexane solvent used for oil extraction were provided 131 by the University of La Rochelle-France. While for fatty acid analysis, 2,3,5132 trimethylhydroquinone $(T M H)$ and iso-octane used to prepare the stock solution for the standards: $\alpha, \beta$, and $\gamma$-Tocopherols for the calibration range of tocopherol analysis with acetone as solvent, were provided by the Institut Polytechnique UniLasalle Beauvais(France), and kept at $-40^{\circ} \mathrm{C}$ for chromatography analyses.

\subsection{Treatment process and Experimental Protocol}

The treatment protocol of oil press-extraction process was achieved at laboratory-scale (Figure 1). In the first part of our experimental study, sunflower seeds were subjected to an instant controlled pressure-drop (DIC) treatment aiming at greatly intensifying oil cold pressextraction.

Figure 1.

142

143

144

145

146

147

148

149

150

151

152

153

154

155

156

157

158

159

160

161

162

163

Some part of the experiments and assessments required a laboratory-scale $n$-hexane solvent extraction. Following the DIC texturing treatment and prior to the properly-said pressing, a drying step was performed. The sunflower seed samples underwent an airflow drying at 40 ${ }^{\circ} \mathrm{C}$ and $1 \mathrm{~m} / \mathrm{s}$, until reaching a final moisture content of $0.060 \pm 0.005 \mathrm{~g} \mathrm{H}_{2} \mathrm{O} / \mathrm{g} \mathrm{db}$. This level is well-known as the most appropriate moisture content for the cold press-extraction. For an assessment requiring a solvent extraction process, the seeds were ground using a laboratory knife mill (RETSCH, Grindomix model GM 200-F; Kurt Retsch GmbH \& Co. KG, Haan, Germany) at 8000 rpm for 40 seconds.

\subsubsection{DIC treatment}

The DIC unit was presented in various articles (Figure 2) (Allaf and Allaf, 2014; Sabah Mounir et al., 2011; and Albitar et al., 2011). The research works carried out on instant controlled pressure-drop technology (DIC) at both fundamental levels and industrial applications have the specificity of a theoretical foundation based on the thermodynamics of instantaneity (Allaf et al., 2014): far from the equilibrium, processes occur between the two-asymptotic behaviors of quasi-static (classical thermodynamics) and instantaneous limits. Processes and transformations occurring in a theoretically zero time (transport of molecules in dozens of milliseconds), generally imply a decrease in the fluctuation degree of the random translational movement of the particles, at the same time an equally instantaneous decrease of the temperature. The relaxation time ( $\Delta$ t of dozens of $\mathrm{ms}$ ) is an essential parameter in the considered processes; it implies a very high pressure-drop rate $\Delta \mathrm{P} / \Delta \mathrm{t}$ often greater than 5 $10^{5} \mathrm{~Pa} \mathrm{~s}^{-1}$. The cooling rate can reach exceptional levels of 1500 to $2000 \mathrm{~kW} / \mathrm{m}^{2}$ of the product (Allaf et al., 2018b).

Figure 2.

DIC has been inserted as relevant process or effective intensification mean for many unit operations of decontamination, drying, extraction, chemical or enzymatic reactive transformations, etc. (Allaf et al., 2014) (Sabah Mounir et al., 2011) (Mounir et al., 2012) 
(Berka-Zougali et al., 2010) (Albitar et al., 2011). Practical treatment with DIC involves a vacuum stage of $5 \mathrm{kPa}$, followed by a HTST (High Temperature-Short Time) type process generally using saturated dry steam absolute pressure (usually ranged between 0.05 and 1 $\mathrm{MPa}$ ), i.e. temperature of $60^{\circ} \mathrm{C}$ to $170{ }^{\circ} \mathrm{C}$ (Besombes et al., 2010). The short treatment time (some dozens of seconds) includes a steam injection step (lasting less than $3 \mathrm{~s}$ ) involving vapor condensation on the product surface (moisture content may increase by $\Delta \mathrm{W}$ of almost $0.1 \mathrm{~g} \mathrm{H}_{2} \mathrm{O} / \mathrm{g} \mathrm{db}$, resulting in soaring heating coefficient up to tens of $\mathrm{kW} \mathrm{m}^{-2} \mathrm{~K}^{-1}$ ), followed by a homogenization step of both thermal and condensed water within the product. Succeeding this roughly balance step, the pressure abruptly drops $\gg>$ towards the vacuum (steam tank maintained at 3 to $5 \mathrm{kPa}$ ) (Allaf and Allaf, 2013).

Instantaneous-type of coupled thermomechanical transformations of DIC is: i/ an autovaporization of a certain quantity of volatile molecules, mainly water to reach the new thermodynamic equilibrium; (the moisture content undergoes a decrease $\Delta \mathrm{W}$ of approximately $-0.11 \mathrm{~g} \mathrm{H}_{2} \mathrm{O} / \mathrm{g} \mathrm{db}$ ), ii/ mechanical stresses within the material resulting in a new structure and texture, iii/ a cooling of the material possibly involving an overshoot beyond of the glass transition. Thus, the new often expanded structure of the matrix is preserved (Haddad et al., 2008), and iv/ while preserving a perfect stop of the thermal 185 degradation.

Following a few preliminary tests, two operating parameters of DIC treatment of sunflower seeds, namely the dry saturated steam absolute pressure $(P)$ ranged between 0.2 and 0.7 $\mathrm{MPa}$, and the treatment time $(\mathrm{t})$ ranged between 15 and $85 \mathrm{~s}$ were selected. DIC-texturing begins by introducing into the treatment vessel a quantity of $150-200 \mathrm{~g}$ of sunflower seeds at $7 \pm 0.2 \% \mathrm{db}$ (dry basis) water content. An initial vacuum makes it possible to greatly reduce the diffusion resistance between the exchange surface and the steam, thus inducing an improvement of the heat transfer.

Hence, after closing the pneumatic valve, the high-pressure steam is injected to reach the desired pressure level (and temperature). It is maintained throughout the treatment until reaching a level of thermal homogeneity and humidity within the material. An abrupt pressure-drop towards the vacuum results in an autovaporization of the water, an instantaneous cooling of the solid material and a possible more or less marked expansion of the product (Mounir et al., 2011). DIC-textured oleaginous seeds have better technological aptitude regarding cold-press extraction with higher oil yield. In order to evaluate and analyze the biochemical composition, DIC-textured seeds are often crushed before an extraction operation with $\mathrm{n}$-hexane.

\subsubsection{Extraction process: Mechanical cold-press extraction}

The present research aims to study the variation of the yield of sunflower oil from the two oleic and linoleic varieties and to compare the results obtained from the treated and untreated matrices. The industrial procedure for extracting sunflower oil is based on the cold-mechanical way (press, cavitator, centrifuge systems...).

At this level, the extraction of oils is based on the mechanical action of press compression. The pressing operation allows the oleaginous seed to liberate the oily liquid contained in the kernel cells and separate it from the residual solid called "cake".

211 which operates according to a continuous process (p500R, Anton Fries Mashinenbau GmbH, 
Germany). It operates at a frequency of $50 \mathrm{~Hz}$, a voltage of $400 \mathrm{~V}$ and a power of $1.5 \mathrm{~kW}$. This device comprises a stainless-steel cylindrical hopper of $35 \mathrm{~mm}$ diameter. In the feeding zone, the seeds are pressed and freely transported under the effect of the mono-screw towards the bottom of a fixed tube to create a high-pressure cold-compression. This fixed tube contains holes along its length through which the oil is recovered at the bottom of the press by a flow through calibrated $8 \mathrm{~mm}$ hole called die or nozzle, positioned at cylinder end to remove the cakes in granular forms. This separation is done in an area called the filtration zone.

Following filtration, the extracted oil was measured while the cake was stored in poly-bag at a temperature of $4{ }^{\circ} \mathrm{C}$. The oil yield is expressed in $\mathrm{g}$ oil/g ddb (dry dry matter, which means a mass basis of raw material rid of water and oil) with an error estimated at $0.05 \%$. Coldpress oil extraction was successively performed on the raw-material (untreated) and DICtextured sunflower seeds after adjusting the moisture content of each sample to $0.06 \pm$ $0.005 \mathrm{~g} \mathrm{H}_{2} \mathrm{O} / \mathrm{g} \mathrm{db}$.

$$
Y_{\text {huile }}(g \text { oil } / g \text { ddb })=\frac{\text { oil mass }}{\text { drydry seed mass }(\text { ddb })}
$$

\subsubsection{Design of Experiments DoE}

\subsubsection{Experimental Protocol}

From literature and previous experience of our research team, succeeding few preliminary tests, a Design of Experiments DoE was defined. In the current case, since our objective was not a simple approach of operational trends, but especially to carry out a relevant optimization study of the main operating parameters of the new industrial treatment DIC operation, we opted for a 5-level 2-parameter Box-Wilson Central Composite Design (CCD). For DIC-texturing, the two operating parameters of the absolute value of saturated dry steam pressure $(\mathrm{P})$ and the treatment time $(\mathrm{t})$ were ranged from 0.2 to $0.7 \mathrm{MPa}$, and from 15 to $85 \mathrm{~s}$, respectively.

The experimental responses were statistically processed using Statgraphics plus software (Statgraphics Centurion XV, StatPoint Technologies, Inc., Rockville, USA). This Response Surface Methodology (RSM) allows highlighting for each dependent variable $(Y)$ the significance level of the DIC factors as independent variables $x_{i}(P$ and $t)$ through ANOVA, $p$ value $(P \leq 0.05)$, and Pareto Charts, as well as the general trends, response surfaces, and isoresponse curves, issued from the empirical second-order polynomial model $Y$ versus the independent variables $x_{i}$, and $R^{2}$ whose value reveals the degree of validity of this empirical model:

$$
Y=\beta_{0}+\sum_{i=1}^{k} \beta_{i} \chi_{i}+\sum_{i=1}^{k} \beta_{i i} \chi_{i}^{2}+\sum_{i=1}^{k-1} \sum_{j=2}^{k} \beta_{i j} \chi_{i} \chi_{j}+\mathcal{E}
$$

Where $Y$ is the response, $\beta_{i}, \beta_{i i}$, and $\beta_{i j}$ are the regression coefficients, $x_{i}$ the independent variables, $\varepsilon$ is a random error, $\mathrm{i}$ and $\mathrm{j}$ are the factor indices. 


\subsection{Assessment methods and processes}

\subsubsection{Measurement of moisture content}

The water content was determined according to the AOAC method (2005) at $105^{\circ} \mathrm{C}$ for 24 hours until a constant weight is obtained.

\subsubsection{Oil extraction by Randall}

Usually, solvent extraction of both whole seed and residual cake (before and after the coldpress extraction, respectively), is carried out as an initial assessment stage to measure the composition of plant-base materials. Frequently, oil solvent extraction system used is "Randall's SER 148/3 model equipment from Velp Scientifica" (Italy). This is a closed loop cycle of oil solvent extraction procedure; i/ starting by bringing to boil solvent in container using a hot plate, ii/ following by solvent vapor condensation through an adequate cooling system, in the same container to wash the product placed in porous cartridge in this container (reflux washing where the solvent regenerated by condensation, flows and washes the sample contained in the cartridge), iv/ ending by a "recovery phase" during which the majority of the solvent is removed and the extracted oil remains in the containers with traces of solvent. Finally, under Sorbonne, the contents are deposited in Pyrex tubes to evaporate and remove the remainder traces of solvent from the evaporator.

In the present case of sunflower seeds, various differently processed, un-textured and DICtextured seeds, and cakes were studied. Before starting the properly said operation, Velp 148/3 parameters were checked out and corrected for compatibility. In the current case, since the solvent used was $\mathrm{n}$-hexane, and the plate temperature was $180{ }^{\circ} \mathrm{C}$, Viton seals were used. A sample of 5 to $7 \mathrm{~g}$ of crushed sunflower was placed in the porous cartridge to receive, by washing, almost $40 \mathrm{ml} \mathrm{n}$-hexane. This operation was carried out in $6 \mathrm{~h}$. For removing the remainder traces of $n$-hexane solvent from the evaporator, the cartridge contents were deposited in $18 \mathrm{ml}$ Pyrex tubes and put under Sorbonne with airflow heated at $65^{\circ} \mathrm{C}$ for $1 \mathrm{~h}$. This extraction operation is faster, ampler, and more effective than a simple maceration extraction. The extracts were weighed using an analytical high-precision balance (with an accuracy of $0.001 \mathrm{~g}$ ) and then stored at $-4{ }^{\circ} \mathrm{C}$ for biochemical analyses. Oil yields were calculated with an estimated error of $\pm 0.0005 \mathrm{~g}$ oil $/ \mathrm{g} \mathrm{ddb}$.

\subsubsection{Determination of the free fatty acids}

Fatty acid separation was performed using the Agilent 19091S-43 GC Gas Chromatography method (Kyoto, Japan). It is a qualitative and quantitative analysis method that serves to separate a very complex mixture of gaseous samples.

The chromatography device comprised a HP-5MS (5\% Phenyl Methyl Siloxane) capillary type column (30 $\mathrm{m} \times 350 \mu \mathrm{m} \times 0.25 \mu \mathrm{m})$, a furnace with initial temperature ranged from 155 to $230^{\circ} \mathrm{C}$ with a speed of $45^{\circ} \mathrm{C} / \mathrm{min}$. The final phase reached a maximum level of $240{ }^{\circ} \mathrm{C}$ and the oven run time was $10 \mathrm{~min}$ for each sample.

The protocol of the fatty acid analysis was to consider for each sample $15 \mu \mathrm{l}$ of sunflower oil mix with $20 \mu \mathrm{l}$ of the $\mathrm{TMH}$, and $800 \mu \mathrm{l}$ of the isooctane and, after stirring for a few seconds in a vortex, it was ready for analysis. A volume $0.8 \mu \mathrm{l}$ of the assembly was eluted and injected using a syringe in split mode and the temperature of the injector was maintained at $270^{\circ} \mathrm{C}$. Once vaporized by the injector, the compounds were entrained in the column by hydrogen 
as carrier gas. Peak integration and identification of fatty acids were based on the use of the mass spectral MS database of the NIST'98 National Library (National Institute of Standards and Technology of the United States (NIST), Gaithersburg, MD, USA).

\subsubsection{Determination of the protein content}

The determination of the protein content was based on the classical DUMAS method carried out by a nitrogen/protein analyzer LECO FP-528, which consists of a total combustion of 100 $\mathrm{mg}$ of homogeneous crushed dried sunflower seeds $\left(24-\mathrm{h}\right.$ oven at $\left.110^{\circ} \mathrm{C}\right)$. A double repetition was required for analysis for each sample.

DUMAS method, which is performed under oxygen and at high temperature does not directly measure the protein content. This allows quantification of the total nitrogen that is expressed as a percentage and using an internationally recognized conversion factor of 6.25 which differs from protein to protein depending on its amino acid composition, equivalent to $0.16 \mathrm{~g}$ of nitrogen per gram of protein is required to convert the measured nitrogen content to a protein content. It's an easy and fast analysis.

\subsubsection{Determination of tocopherol content}

The determination of the tocopherol content of the sunflower oils was performed using High Performance Liquid Chromatography HPLC (SpectraPhysics, Thermo Separation Products, USA) in $40 \mathrm{~min}$. The multi- $\lambda$ French standard measurement ISO 9936, 1997 implies a complete separation of the 4 forms of tocopherol $\alpha, \beta, \gamma$, and $\delta$ using a fluorescence detector with $298 \mathrm{~nm}$ as excitation wavelength, and $344 \mathrm{~nm}$ as emission wavelength (Velasco and Dobarganes, 2002).

The protocol of the tocopherol analysis was to consider a sample of $1 \mathrm{~g}$ of sunflower oil, and add $1 \mathrm{ml}$ of acetone in a Vial; then the whole was vortexed a few seconds and directly injected into the HPLC system for analysis. The sum of the concentrations $\alpha-, \beta-, \gamma^{-}$, and $\delta$ tocopherol is used to determine the total tocopherol expressed in $\mu \mathrm{g} / \mathrm{g}$ oil.

In the current case, the mobile phase was composed of a mixture $(75: 25 \mathrm{v} / \mathrm{v})$ of acetone and methanol with a flow rate of $1 \mathrm{~cm}^{3} / \mathrm{min}$, provided by the HPLC Delta Chrom SDS 030 pump. The tocopherols were separated by the reversed phase $\mathrm{C} 18$ column at $30^{\circ} \mathrm{C}, 250 \mathrm{~mm} * 4.6$ $\mathrm{mm}$, and $5 \mu \mathrm{m}$ as particle size (Macherey-Nagel Ltd., Düren, Germany). Quantification of the results was evaluated and integrated by comparison with the retention time collected with those of the respective standard surfaces using the chromatographic station software CSW 32 (Data Apex Ltd., Prague, Czech Republic).

\section{Results and Discussions}

\subsection{Effect of DIC-texturing on cold-press extraction}

In the current study, since the yields are expressed in terms of g Oil/g ddb (dry dry basis), we estimated the cold-press extraction yield by subtracting the oil content of the residual cake oil content $\mathbf{Y}_{\text {cake }}$ from the initial sunflower seed $\mathbf{Y}_{\text {whole-seed, }}$ both obtained by performing solvent extraction ( $n$-hexane) using the Randall velp-148 for $6 \mathrm{~h}$ :

$$
Y_{\text {press }}=Y_{\text {whole-seeds }}-Y_{\text {cake }}
$$


To better recognize the comparative aspect of DIC processing in terms of yield enhancement, we used the ratio of improvement of oil extraction (RIE) expressed as a percentage, between DIC-textured and raw-material seeds:

$$
R I E=\frac{Y_{\text {randall } ; D I C}}{Y_{\text {randall } ; R M}}
$$

\section{Table 1.}

Table 1 and Figure 3 show the impact of DIC-texturing under different treatment conditions on cold-press oil yields expressed in (g oil/g ddb dry dry basis) of linoleic and oleic sunflower seeds. Thus, the whole DIC-textured linoleic seeds had an increased oil content $\mathrm{Y}_{\text {whole-seeds }}$ from $0.6519 \mathrm{~g}$ oil/g ddb for raw non-textured seeds up to $0.7208 \mathrm{~g}$ oil $/ \mathrm{g}$ ddb, which means RIE of $111 \%$ RIE. Similar behavior was observed for oleic seeds; the increasing of the oil content of DIC-textured seeds was from $0.6639 \mathrm{~g}$ oil/g ddb for the raw non-textured seeds up to $0.7363 \mathrm{~g}$ oil/g ddb (or RIE=111\%) of the whole DIC-textured oleic seeds. This should be due to an increasing of availability resulting from the higher porosity and possibly the broken cell walls by DIC-texturing triggered on the matrix.

Figure 3.

For both technologic and economic reasons, industries require reaching the highest coldpress extraction yields $\mathbf{Y}_{\text {press. }}$ DIC-texturing at $0.2 \mathrm{MPa}$ for $50 \mathrm{~s}$ resulted in dramatically increasing of the cold-press yield of linoleic of $146 \%$ RIE, which means 0.3462 against $0.5060 \mathrm{~g}$ oil/g ddb for non-treated seeds. Similar results were obtained for oleic seeds DICtreated at $0.5 \mathrm{MPa}$ for $50 \mathrm{~s}$, with $\mathrm{RIE}=132 \%$ and cold press yield of 0.5206 against 0.3950 $\mathrm{g}$ oil/g ddb for non-treated seeds. It is worth highlighting that DIC-texturing pretreatment allows increasing the cold press yields respect to the whole seed yields by about $20 \%$, from $53.11 \%$ to $73.56 \%$ for linoleic variety and $12 \%$, from $59.50 \%$ to $71.64 \%$, for oleic variety (Table 1).

Moreover, the effects of operating parameters of DIC treatment such as saturated vapor pressure $(P)$ and heat treatment time $(t)$ on the yields of oil, and the contents in the cake and in the whole seeds ( $\mathbf{Y}_{\text {press }} ; \mathbf{Y}_{\text {cake; }} \mathbf{Y}_{\text {whole-seeds }}$ ) were statistically analyzed by the statgraphic software (Figure 3).

Table 2.

Table 3.

It is worth noticing that the standardized Pareto Chart (Figure 3.A) shows a significant effect of saturated dry steam pressure $(P)$ and treatment time $(t)$ on the cold-press oil yield $\mathbf{Y}_{\text {press, }}$ residual oil content $\mathbf{Y}_{\text {cake, }}$ and oil content in whole seeds $\mathbf{Y}_{\text {whole-seeds }}$ with $p$ value of 0.05 . The mean absolute error (MAE) is computed as the sum of the squared error values and is the most commonly used lack-of-fit indicator in statistical fitting procedures.

Thus, the empirical second-order regression models of $\mathbf{Y}_{\text {press, }} \mathbf{Y}_{\text {cake, }}$ and $\mathbf{Y}_{\text {whole-seeds }}$ versus the DIC processing parameters were computed. For linoleic variety, they had regression coefficients $R^{2}$ of $83.66 \%, 87.78 \%$, and $90.62 \%$, respectively, and MAE of $0.01395,0.01313$, and 0.00308 , respectively (Table2). Similar study was performed in oil extraction from the oleic variety. They had regression coefficients $\mathrm{R}^{2}$ of $69.62 \%, 67.02 \%$ and $91.14 \%$, respectively, and the MAE were $0.03575,0.03692$, and 0.00395 , respectively (Table 3 ). 


\subsection{Impact of DIC on the quality of the final sunflower seed cake}

Despite the great positive incidence of DIC-texturing on technological aptitudes of cold-oil pressing, it was noteworthy to study the impact of such DIC-texturing on the quality of both extracted oil and cake of sunflower. The specificity of great enhancement of oil yields by DICtexturing would not be so interesting without the perfect preservation of the main compounds and active molecules of sunflower seeds. Indeed, the conventional heating of oilseeds often leads to an increase in oil yields, but it also causes a great deterioration in the quality of both extracted oil and cake. As HTST (high temperature/short time) treatment, DIC often allows the concerned material to preserve its quality. Therefore, it was essential to carry out a detailed study of the impact of DIC-texturing on the composition of cake in proteins, and the oil in fatty acids and the availability of tocopherol.

\subsubsection{Evolution of protein content of the sunflower whole seeds and press-cake vs DIC treatment conditions.}

Table 4.

Figure 4.

The analyses of the total proteins were performed by the classical DUMAS method in the cases of the whole sunflower seeds and cakes at different conditions of DIC treatments, in comparison with the untreated seeds for both linoleic and oleic varieties.

Table 4 illustrates the results of this study and shows that the total protein content had no (or weak) change between the DIC treated and untreated samples; Figure 4 expresses a significantly absence of any effect.

\subsubsection{Evolution of fatty acid contents of sunflower oil versus DIC treatment conditions}

The composition on saturated and unsaturated fatty acids of the whole sunflower seeds and meal, mainly includes palmitic acid (C16:0), stearic acid (C18:0), oleic acid (C18:1), and linoleic acid (C18:2) of the two linoleic and oleic varieties are presented in Table 5.

The GC (Gas Chromatography) analyses proves that, whatever the processing conditions were, DIC texturing triggered no significant change in the fatty acid composition compared to the non-textured (RM) seeds. On the other hand, this observation was confirmed by the statistical analyses through Pareto Charts which reveal the analysis of the variance (ANOVA). Figure 5 highlights that, whatever the fatty acid compounds were, there was a significantly no effect for both whole seeds and cake of the two linoleic and oleic varieties.

Table 5.

Figure 5.

\subsubsection{Tocopherol content of sunflower oil versus DIC treatment conditions}

Table 6 presents the contents of total tocopherol and its forms $(\beta, \gamma$ and $\alpha)$ of sunflower seed oils of the two linoleic and oleic varieties. These values were assessed by HPLC high performance liquid chromatography, for differently DIC textured and non-textured (RM) processing conditions.

The weak variation in tocopherol contents in both seed oil and cake, indicates that there was no change between the DIC-textured and non-textured samples. Moreover, the statistical 
analyses represented by Pareto Charts show a significantly no effect of the DIC parameters of the two linoleic and oleic varieties. This confirms that there was no degradation of the tocopherol contents (Figure 6).

Table 6.

Figure 6.

\section{Conclusion}

The great interest of industry manufacturing the sunflower oil in increasing the yields while preserving the quality of both oil and cake, as well as defining a new deodorization process was the basis of our investigation on the effect of texturing by instant controlled pressuredrop (DIC) on the press extraction of sunflower oil, respectively. DIC-texturing has allowed great impact on cold-press oil yields, reaching an increasing press-oil yields by about $46 \%$ and $32 \%$, for linoleic and oleic varieties, respectively. Since DIC is a HTST (High Temperature/Short Time) operation, it normally results in the conservation of the biochemical composition of the material and a total preservation of the biochemical composition of both final products; oil and cake. The multi-criteria optimization of the DIC operating parameters, namely the saturated dry steam pressure $(P)$ and the processing time $(t)$, using a 5-level Central Composite Design (CCD) of Experimental Design (DoE) and prominently statistical analyses of the experimental results, highlighted the direct significant effect of the operating parameters $P$ and $t$ on the DIC performance. The highest yield of cold-press oil extraction has corresponded to $50 \mathrm{~s}$ of treatment time, with 0.2 and $0.5 \mathrm{MPa}$ as saturated dry steam pressure, for linoleic and oleic varieties, respectively.

Thus, the Instant Controlled Pressure-Drop DIC texturation as a means of possible modification of the raw material structure appears getting great impact on increasing yields of the cold-press extraction of oil, on preserving the quality of both oil and residual cake with no change between the DIC textured and non-textured samples.

\section{Reference}

Al Mahmud, K.A.H., Zulkifli, N.W.M., Masjuki, H.H., Varman, M., Kalam, M.A., Mobarak, H.M., Imran, A., Shahir, S.A., 2013. Working Temperature Effect of A-C: H/A-C: H and Steel/Steel Contacts on Tribo Properties in Presence of Sunflower Oil as a Bio Lubricant. Procedia Eng., INTERNATIONAL TRIBOLOGY CONFERENCE MALAYSIA 2013 68, 550-557. https://doi.org/10.1016/j.proeng.2013.12.220

Albitar, N., Mounir, S., Besombes, C., Allaf, K., 2011. Improving the Drying of Onion Using the Instant Controlled Pressure Drop Technology. Dry. Technol. 29, 993-1001. https://doi.org/10.1080/07373937.2010.507912

Allaf, T., Allaf, K., 2013. Instant Controlled Pressure Drop (D.I.C.) in Food Processing: From Fundamental to Industrial Applications. Springer Science \& Business Media.

Allaf, T., Fine, F., Tomao, V., Nguyen, C., Ginies, C., Chemat, F., 2014. Impact of instant controlled pressure drop pre-treatment on solvent extraction of edible oil from rapeseed seeds. OCL 21, A301. https://doi.org/10.1051/ocl/2014002 
Allaf, T., Tomao, V., Ruiz, K., Bachari, K., El Maataoui, M., Chemat, F., 2018a. Deodorization by instant controlled pressure drop autovaporization of rosemary leaves prior to solvent extraction of antioxidants. LWT - Food Sci. Technol. 51, 51. https://doi.org/10.1016/j.lwt.2012.11.07

Allaf, T., Tomao, V., Ruiz, K., Chemat, F., 2018b. Instant controlled pressure drop technology and ultrasound assisted extraction for sequential extraction of essential oil and $\begin{array}{llll}\text { antioxidants. } & \text { Ultrason. } & \end{array}$ https://doi.org/10.1016/j.ultsonch.2012.05.013

Ayerdi Gotor, A., Berger, M., Labalette, F., Centis, S., Daydé, J., Calmon, A., 2016. Comparative analysis of fatty acids, tocopherols and phytosterols content in sunflower cultivars (Helianthus annuus) from a three-year multi-local study. Phyton Int. J. Exp. Bot. 84, 14-25.

Ayerdi-Gotor, A., Berger, M., Labalette, F., Centis, S., Eychenne, V., Daydé, J., Calmon, A., 200811-12. Variabilité des teneurs et compositions des composés mineurs dans I'huile de tournesol au cours du développement du capitule. Oleacuteagineux Corps Gras Lipides 400-406. https://doi.org/10.1684/ocl.2008.0227

Berka-Zougali, B., Hassani, A., Besombes, C., Allaf, K., 2010. Extraction of essential oils from Algerian myrtle leaves using instant controlled pressure drop technology. J. Chromatogr. A 1217, 6134-6142. https://doi.org/10.1016/j.chroma.2010.07.080

Besombes, C., Berka-Zougali, B., Allaf, K., 2010. Instant controlled pressure drop extraction of lavandin essential oils: Fundamentals and experimental studies. J. Chromatogr. A 1217, 6807-6815. https://doi.org/10.1016/j.chroma.2010.08.050

Bouallegue, K., Allaf, T., Besombes, C., Younes, R.B., Allaf, K., 2015. Phenomenological modeling and intensification of texturing/grinding-assisted solvent oil extraction: case of date seeds (Phoenix dactylifera L.). Arab. J. Chem. https://doi.org/10.1016/j.arabjc.2015.03.014

Bouallegue, K., Allaf, T., Younes, R.B., Allaf, K., 2016. Texturing and Instant Cooling of Rapeseed as Pretreatment Prior to Pressing and Solvent Extraction of Oil. Food Bioprocess Technol. 9, 1521-1534. https://doi.org/10.1007/s11947-016-1734-x

Boutin, O., Badens, E., 2009. Extraction from oleaginous seeds using supercritical CO2: Experimental design and products quality. J. Food Eng. 4, 396-402. https://doi.org/10.1016/j.jfoodeng.2008.12.007

Carasek, E., Pawliszyn, J., 2006. Screening of Tropical Fruit Volatile Compounds Using SolidPhase Microextraction (SPME) Fibers and Internally Cooled SPME Fiber. J. Agric. Food Chem. 54, 8688-8696. https://doi.org/10.1021/jf0613942

Castro, C., Leite, R.M.V.B.C., 2018. Main aspects of sunflower production in Brazil. OCL 25, D104. https://doi.org/10.1051/ocl/2017056

Connor, D.J., Hall, A.J., 1997. Sunflower Physiology. Sunflower Technol. Prod. agronomymonogra, 113-182. https://doi.org/10.2134/agronmonogr35.c4

Cường N.V., 2013. IMPACT OF TEXTURING BY INSTANT CONTROLLED PRESSURE DROP (DIC) ON SOLVENT EXTRACTION OF JATROPHA CURCAS OIL. Hue Univ. J. Sci. HU JOS 69. 
Del Gatto, A., Melilli, M.G., Raccuia, S.A., Pieri, S., Mangoni, L., Pacifico, D., Signor, M., Duca, D., Foppa Pedretti, E., Mengarelli, C., 2015. A comparative study of oilseed crops (Brassica napus L. subsp. oleifera and Brassica carinata A. Braun) in the biodiesel production chain and their adaptability to different Italian areas. Ind. Crops Prod., Valorization of biodiesel chain co-products in a biorefinery framework 75, 98-107. https://doi.org/10.1016/j.indcrop.2015.04.029

Gunstone, F., 2009. The Chemistry of Oils and Fats: Sources, Composition, Properties and Uses. John Wiley \& Sons.

Haddad, M.A., Mounir, S., Sobolik, V., Allaf, K., 2008. Fruits \& Vegetables Drying Combining Hot Air, DIC Technology and Microwaves. Int. J. Food Eng. 4. https://doi.org/10.2202/1556-3758.1491

Heiser, C.B., 2008. The sunflower (<Emphasis Type="Italic" $>$ Helianthus annuus</Emphasis $>$ ) in Mexico: further evidence for a North American domestication. Genet. Resour. Crop Evol. 55, 9-13. https://doi.org/10.1007/s10722-007-9300-z

Isobe, S., Zuber, F., Uemura, K., Noguchi, A., 1992. A new twin-screw press design for oil extraction of dehulled sunflower seeds. J. Am. Oil Chem. Soc. 69, 884-889. https://doi.org/10.1007/BF02636338

Ixtaina, V.Y., Martínez, M.L., Spotorno, V., Mateo, C.M., Maestri, D.M., Diehl, B.W.K., Nolasco, S.M., Tomás, M.C., 2011. Characterization of chia seed oils obtained by pressing and solvent extraction. J. Food Compos. Anal. 24, 166-174. https://doi.org/10.1016/j.jfca.2010.08.006

Kruidenberg, M., 2009. Method for processing vegetable oils. US7598407B2.

Leão, K.M.M., Sampaio, K.L., Pagani, A.A.C., Da Silva, M.A.A.P., 2014. Odor potency, aroma profile and volatiles composition of cold pressed oil from industrial passion fruit residues. Ind. Crops Prod. 58, 280-286. https://doi.org/10.1016/j.indcrop.2014.04.032

Moreau, R.A., Whitaker, B.D., Hicks, K.B., 2002. Phytosterols, phytostanols, and their conjugates in foods: structural diversity, quantitative analysis, and health-promoting uses. Prog. Lipid Res. 41, 457-500. https://doi.org/10.1016/S0163-7827(02)00006-1

Mounir, S., Allaf, T., Mujumdar, A.S., Allaf, K., 2012. Swell Drying: Coupling Instant Controlled Pressure Drop DIC to Standard Convection Drying Processes to Intensify Transfer Phenomena and Improve Quality-An Overview. Dry. Technol. 30, 1508-1531. https://doi.org/10.1080/07373937.2012.693145

Mounir, S., Besombes, C., Al-Bitar, N., Allaf, K., 2011. Study of Instant Controlled Pressure Drop DIC Treatment in Manufacturing Snack and Expanded Granule Powder of Apple and Onion. Dry. Technol. 29, 331-341. https://doi.org/10.1080/07373937.2010.491585

Mounir, Sabah, Halle, D., Allaf, K., 2011. Characterization of pure cheese snacks and expanded granule powders textured by the instant controlled pressure drop (DIC) process. Dairy Sci. Technol. 91, 441. https://doi.org/10.1007/s13594-011-0023-8 
Pal, U.S., Patra, R.K., Sahoo, N.R., Bakhara, C.K., Panda, M.K., 2015. Effect of refining on quality and composition of sunflower oil. J. Food Sci. Technol. 52, 4613-4618. https://doi.org/10.1007/s13197-014-1461-0

Pelletier, X., Belbraouet, S., Mirabel, D., Mordret, F., Perrin, J.L., Pages, X., Debry, G., 1995. A diet moderately enriched in phytosterols lowers plasma cholesterol concentrations in normocholesterolemic humans. Ann. Nutr. Metab. 39, 291-295. https://doi.org/10.1159/000177875

Rashid, U., Anwar, F., Moser, B.R., Ashraf, S., 2008. Production of sunflower oil methyl esters by optimized alkali-catalyzed methanolysis. Biomass Bioenergy 32, 1202-1205. https://doi.org/10.1016/j.biombioe.2008.03.001

Roche, J., Essahat, A., Bouniols, A., Asri, M.E., Mouloungui, Z., Mondiès, M., Alghoum, M., 2004. (Helianthus annuus L.) SEEDS WITHIN CULTURAL 26.

Van, C.N., 2010. Maîtrise de l'aptitude technologique des oléagineux par modification structurelle : applications aux opérations d'extraction et de transestérification in-situ (phdthesis). Université de La Rochelle.

Velasco, J., Dobarganes, C., 2002. Oxidative stability of virgin olive oil. Eur. J. Lipid Sci. Technol. 104, 661-676. https://doi.org/10.1002/14389312(200210)104:9/10<661::AID-EJLT661>3.0.CO;2-D 


\section{Table captions}

Table 1. Cold-press $Y_{\text {press, }}$ solvent extracted Residual cake oil $Y_{\text {cake, }}$ and total whole-seed oil yields $Y_{\text {whole-seeds, }}$ expressed in $g$ Oil/g db (dry basis: material mass devoid from water content) and $g$ Oil/g ddb (dry dry basis: material mass devoid from water and oil contents) of the linoleic and oleic variety for untreated and differently DIC-treated sunflower seeds.

Table 2. The empirical models retained from the second-order regression of linoleic variety

Table 3. The empirical models retained from the second-order regression of oleic variety

Table 4. Protein contents of whole seeds and cake of sunflower versus different DIC treatment conditions.

Table 5. Saturated and unsaturated fatty acid amount of the whole seed and of the cake of sunflower for Linoleic and oleic variety of different DIC treatment conditions

Table 6. Tocopherol contents of the sunflower oil for the Linoleic and Oleic varieties of different Instant Controlled Pressure-Drop DIC treatment conditions.

\section{Figure captions}

Figure 1. Applied protocol of sunflower seed

Figure 2. Instant controlled pressure-drop (DIC) laboratory-scale unit.

Figure 3. Effect of Instant Controlled Pressure-Drop DIC parameters on oil yields by cold-press extraction, cake oil concentration and whole oil concentration of differently DIC-textured sunflower seeds: A) Standardized Pareto Chart; B) Separated direct effects and C) Estimated response area.

Figure 4. Standardized Pareto charts of Instant Controlled Pressure-Drop DIC pretreatment for protein content of the sunflower whole seeds and cake for linoleic and oleic varieties versus DIC processing parameters $\mathrm{P}$ (saturated dry steam) and $\mathrm{t}$ (processing time)..

Figure 5. Standardized Pareto Charts of DoE of Instant Controlled Pressure-Drop DIC for fatty acid amounts of sunflower whole seeds and cakes for linoleic varieties versus DIC processing parameters P (saturated dry steam) and t (processing time)..

Figure 6. Standardized Pareto Charts for Tocopherol contents of whole sunflower seeds for linoleic and oleic variety versus Instant Controlled Pressure-Drop DIC processing parameters $\mathrm{P}$ (saturated dry steam) and $\mathrm{t}$ (processing time). 
Table 1.

\begin{tabular}{|c|c|c|c|c|c|c|c|c|c|c|c|c|}
\hline \multicolumn{3}{|c|}{ Linoleic variety } & \multicolumn{3}{|c|}{$Y_{\text {press }}$} & \multicolumn{3}{|c|}{$Y_{\text {cake }}$} & \multicolumn{3}{|c|}{$Y_{\text {whole seeds }}$} & \multirow{2}{*}{$Y_{\text {press }} / Y_{\text {whole-seeds }}$} \\
\hline Run no & $\mathrm{P}(\mathrm{MPa})$ & $t(s)$ & g Oil/g db & g Oil/g ddb & RIE\% & g Oil/g db & g Oil/g ddb & RIE\% & g Oil/g db & g Oil/g ddb & RIE\% & \\
\hline RM & - & - & 0.2096 & 0.3462 & $100 \%$ & 0.2341 & 0.3057 & $100 \%$ & 0.3946 & 0.6519 & $100 \%$ & $53.11 \%$ \\
\hline DIC 1 & 0.5 & 50 & 0.2147 & 0.3649 & $105 \%$ & 0.2508 & 0.3348 & $110 \%$ & 0.4117 & 0.6997 & $107 \%$ & $52.16 \%$ \\
\hline DIC 2 & 0.7 & 50 & 0.2527 & 0.4317 & $125 \%$ & 0.2167 & 0.2767 & $91 \%$ & 0.4146 & 0.7084 & $109 \%$ & $60.94 \%$ \\
\hline DIC 3 & 0.5 & 85 & 0.2382 & 0.4057 & $117 \%$ & 0.2292 & 0.2974 & $97 \%$ & 0.4128 & 0.7030 & $108 \%$ & $57.70 \%$ \\
\hline DIC 4 & 0.5 & 50 & 0.2002 & 0.3418 & $99 \%$ & 0.2676 & 0.3654 & $120 \%$ & 0.4142 & 0.7071 & $108 \%$ & $48.33 \%$ \\
\hline DIC 5 & 0.6 & 74.7 & 0.2488 & 0.4281 & $124 \%$ & 0.2264 & 0.2927 & $96 \%$ & 0.4189 & 0.7208 & $111 \%$ & $.40 \%$ \\
\hline DIC 6 & 0.6 & 25.3 & 0.2125 & 0.3571 & $103 \%$ & 0.2443 & 0.3233 & $106 \%$ & 0.4049 & 0.6804 & $104 \%$ & $52.48 \%$ \\
\hline DIC 7 & 0.5 & 50 & 0.2632 & 471 & $129 \%$ & 0.2011 & 0.2517 & $82 \%$ & 114 & 989 & $107 \%$ & $8 \%$ \\
\hline DIC 8 & 0.3 & 25.3 & 0.2689 & 0.4522 & $131 \%$ & 0.1866 & 0.2294 & $75 \%$ & 0.4053 & 0.6816 & $105 \%$ & $66.34 \%$ \\
\hline DIC 9 & 0.3 & 74.7 & 0.2622 & 0.4411 & $127 \%$ & 0.1944 & 0.2413 & $79 \%$ & 56 & 324 & $105 \%$ & $4 \%$ \\
\hline DIC 10 & 0.5 & 50 & 0.2572 & 0.4346 & $126 \%$ & 0.2033 & 0.2552 & $83 \%$ & 0.4082 & 398 & $106 \%$ & $1 \%$ \\
\hline DIC 11 & 0.2 & 50 & 0.2998 & 0.5060 & $146 \%$ & 0.1539 & 0.1819 & $60 \%$ & 0.4076 & 0.6879 & $106 \%$ & $6 \%$ \\
\hline DIC 12 & 0.5 & 15 & 0.2733 & 0.4569 & $132 \%$ & 0.1769 & 0.2149 & $70 \%$ & 0.4019 & 0.6718 & $103 \%$ & $68.01 \%$ \\
\hline DIC 13 & 0.5 & 50 & 0.2564 & 0.4342 & $125 \%$ & 0.2058 & 0.2591 & $85 \%$ & 0.4094 & 0.6933 & $106 \%$ & $62.62 \%$ \\
\hline \multicolumn{3}{|c|}{ Oleic variety } & \multicolumn{3}{|c|}{$Y_{\text {press }}$} & \multicolumn{3}{|c|}{$Y_{\text {cake }}$} & \multicolumn{3}{|c|}{$Y_{\text {whole-seeds }}$} & \multirow{2}{*}{$Y_{\text {press }} / Y_{\text {whole-seeds }}$} \\
\hline Run no & $\mathrm{P}(\mathrm{MPa})$ & $\mathrm{t}(\mathrm{s})$ & g Oil/g db & g Oil/g ddb & RIE\% & g Oil/g db & g Oil/g ddb & RIE\% & $\mathrm{g}$ Oil/g db & g Oil/g ddb & RIE\% & \\
\hline RM & - & - & 0.2374 & 0.395005 & $100 \%$ & 0.2119 & 0.2688745 & $100 \%$ & 0.3990 & 0.6638795 & $100 \%$ & $59.50 \%$ \\
\hline DIC 1 & 0.5 & 50 & 0.2436 & 0.4175983 & $106 \%$ & 0.2288 & 0.2966805 & $110 \%$ & 0.4167 & 0.7142788 & $108 \%$ & $58.46 \%$ \\
\hline DIC 2 & 0.7 & 50 & 0.1266 & 0.2183322 & $55 \%$ & 0.3361 & 0.5062509 & $188 \%$ & 0.4201 & 0.7245832 & $109 \%$ & $30.13 \%$ \\
\hline DIC 3 & 0.5 & 85 & 0.2989 & 0.5189654 & $131 \%$ & 0.1785 & 0.2172855 & $81 \%$ & 0.4240 & 0.7362508 & $111 \%$ & $49 \%$ \\
\hline DIC 4 & 0.5 & 50 & 0.3015 & 0.5206118 & $132 \%$ & 0.1709 & 0.2061271 & $77 \%$ & 0.4209 & 0.7267389 & $109 \%$ & $71.64 \%$ \\
\hline DIC 5 & 0.6 & 75 & 0.2908 & 0.5028691 & $127 \%$ & 0.1846 & 0.226392 & $84 \%$ & 0.4217 & 0.7292611 & $110 \%$ & $68.96 \%$ \\
\hline DIC 6 & 0.6 & 25 & 0.2683 & 0.4539809 & $115 \%$ & 0.1923 & 0.2380834 & $89 \%$ & 0.4090 & 0.6920643 & $104 \%$ & $65.60 \%$ \\
\hline DIC 7 & 0.5 & 50 & 0.265 & 0.454888 & $115 \%$ & 0.2074 & 0.2616705 & $97 \%$ & 0.4174 & 0.7165584 & $108 \%$ & $63.48 \%$ \\
\hline DIC 8 & 0.3 & 25 & 0.2668 & 0.4530433 & $115 \%$ & 0.1968 & 0.2450199 & $91 \%$ & 0.4111 & 0.6980632 & $105 \%$ & $64.90 \%$ \\
\hline DIC 9 & 0.3 & 75 & 0.2802 & 0.4789306 & $121 \%$ & 0.1872 & 0.230315 & $86 \%$ & 0.4149 & 0.7092456 & $107 \%$ & $67.53 \%$ \\
\hline DIC 10 & 0.5 & 50 & 0.2814 & 0.4840479 & $123 \%$ & 0.191 & 0.2360939 & $88 \%$ & 0.4187 & 0.7201419 & $108 \%$ & $67.22 \%$ \\
\hline DIC 11 & 0.2 & 50 & 0.2649 & 0.4468739 & $113 \%$ & 0.1936 & 0.2400794 & $89 \%$ & 0.4072 & 0.6869533 & $103 \%$ & $65.05 \%$ \\
\hline DIC 12 & 0.5 & 15 & 0.2648 & 0.4484239 & $114 \%$ & 0.1968 & 0.2450199 & $91 \%$ & 0.4095 & 0.6934439 & $104 \%$ & $64.67 \%$ \\
\hline DIC 13 & 0.5 & 50 & 0.2865 & 0.4932339 & $125 \%$ & 0.1859 & 0.2283503 & $85 \%$ & 0.4191 & 0.7215842 & $109 \%$ & $68.35 \%$ \\
\hline
\end{tabular}


Table 2. The empirical models retained from the second-order regression of linoleic variety

\begin{tabular}{cc}
\hline$Y_{\text {press }}=1.063-1.918 p-0.0078 t+1.744 p^{2}+0.00384 p t+0.000059 t^{2}$ & $R^{2}=83.658 \%$ \\
\hline$Y_{\text {cake }}=-0.39267+1.884 p+0.00830 t-1.79356 p^{2}-0.00127 p t-0.0000712 t^{2}$ & $R^{2}=87.784 \%$ \\
\hline$Y_{\text {whole-seeds }}=0.7011-0.1225 p+0.00005 t+0.04908 p^{2}+0.002562 P t-0.0000084 t^{2}$ & $R^{2}=90.623 \%$
\end{tabular}


Table3. The empirical models retained from the second-order regression of oleic variety

\begin{tabular}{cc}
\hline$Y_{\text {press }}=0.1728+1.825 p-0.00201 t-2.412 p^{2}+0.00173 p t+0.000021 t^{2}$ & $R^{2}=69.617 \%$ \\
\hline$Y_{\text {cake }}=0.478833-1.67217 p+0.00226992 t+2.20435 p^{2}+0.0000565 p t-0.000026 t^{2}$ & $R^{2}=67.018 \%$ \\
\hline$Y_{\text {whole-seeds }}=0.65164+0.1524 p+0.0002576 t-0.2079 p^{2}+0.00179 P t-0.0000056 t^{2}$ & $R^{2}=91.137 \%$
\end{tabular}

577 
578 Table 4. Protein contents of whole seeds and cake of sunflower versus different DIC treatment conditions.

\begin{tabular}{lcc}
\multirow{2}{*}{ run n } & \multicolumn{2}{c}{ linoleic variety } \\
\cline { 2 - 3 } DIC 1 & whole seeds & sunflower cake \\
\hline DIC 2 & 17.87 & 22.91 \\
\hline DIC 3 & 18.11 & 22.56 \\
\hline DIC 4 & 17.31 & 22.22 \\
\hline DIC 5 & 17.71 & 23.36 \\
\hline DIC 6 & 17.61 & 23.65 \\
\hline DIC 7 & 18.01 & 22.53 \\
\hline DIC 8 & 18.51 & 23.81 \\
\hline DIC 9 & 20.47 & 25.91 \\
\hline DIC 10 & 17.55 & 25.46 \\
\hline DIC 11 & 18.80 & 25.03 \\
\hline DIC 12 & 17.77 & 25.66 \\
\hline DIC 13 & 17.67 & 25.91 \\
\hline <RM> & 17.71 & 23.22 \\
\hline <DIC & $18.06 \pm 0.80$ & $25.59 \pm 0.66$ \\
\hline
\end{tabular}

$579<$ RM>: Average of Raw Material samples

$580<$ DIC $>$ : Average of DIC treatments 


\begin{tabular}{ccccccccc} 
& \multicolumn{7}{c}{ Linoleic variety } \\
\cline { 2 - 11 } & \multicolumn{7}{c}{ whole seed of sunflower } & \multicolumn{5}{c}{ cake of sunflower } \\
\hline Trial n & \multicolumn{1}{c}{ C16:0 } & C18:0 & C18:1 & C18:2 & C16:0 & C18:0 & C18:1 & C18:2 \\
\hline DIC 1 & 6.79 & 4.24 & 23.08 & 64.12 & 6.68 & 4.29 & 25.89 & 62.49 \\
\hline DIC 2 & 6.65 & 4.17 & 22.91 & 64.69 & 6.78 & 4.33 & 24.13 & 64.11 \\
\hline DIC 3 & 6.71 & 4.27 & 23.54 & 63.77 & 6.88 & 4.38 & 24.37 & 63.72 \\
\hline DIC 4 & 6.60 & 4.14 & 23.84 & 63.68 & 6.83 & 4.47 & 24.71 & 62.99 \\
\hline DIC 5 & 6.58 & 4.27 & 23.25 & 64.09 & 6.83 & 4.47 & 24.77 & 63.26 \\
\hline DIC 6 & 6.51 & 4.17 & 23.25 & 64.34 & 6.83 & 4.43 & 24.38 & 62.97 \\
\hline DIC 7 & 6.45 & 4.21 & 23.47 & 63.98 & 6.89 & 4.54 & 25.14 & 62.37 \\
\hline DIC 8 & 6.44 & 4.18 & 23.28 & 63.98 & 6.88 & 5.00 & 24.53 & 63.09 \\
\hline DIC 9 & 6.49 & 4.18 & 23.68 & 63.74 & 6.95 & 4.52 & 24.63 & 63.22 \\
\hline DIC 10 & 6.48 & 4.11 & 23.10 & 64.43 & 6.96 & 4.66 & 25.12 & 62.20 \\
\hline DIC 11 & 6.52 & 4.25 & 23.55 & 63.97 & 7.12 & 4.57 & 24.70 & 62.92 \\
\hline DIC 12 & 6.65 & 4.38 & 24.04 & 63.29 & 6.96 & 4.80 & 25.18 & 61.95 \\
\hline DIC 13 & 6.56 & 4.16 & 23.70 & 63.78 & 6.96 & 4.74 & 25.45 & 61.76 \\
\hline$<$ RM $>$ & $6.75 \pm 0.02$ & $4.354 \pm 0.06$ & $24.14 \pm 0.16$ & $63.28 \pm 0.17$ & $6.73 \pm 0.07$ & $4.41 \pm 0.24$ & $24.23 \pm 0.71$ & $63.75 \pm 1.34$ \\
\hline$<$ DIC $>$ & $6.57 \pm 0.11$ & $4.209 \pm 0.07$ & $23.45 \pm 0.33$ & $63.99 \pm 0.36$ & $6.89 \pm 0.11$ & $4.56 \pm 0.15$ & $24.85 \pm 0.49$ & $62.85 \pm 0.68$
\end{tabular}



Controlled Pressure-Drop DIC treatment conditions.

\begin{tabular}{ccccc}
\multicolumn{5}{c}{ Linoleic variety } \\
\hline Trial n & $\beta$ & $\gamma$ & $\alpha$ & TTP \\
\hline DIC-1 & 11.64 & 12.86 & 166.74 & 191.24 \\
\hline DIC-2 & 12.16 & 13.97 & 216.98 & 243.1 \\
\hline DIC-3 & 10.63 & 13.69 & 188.26 & 212.59 \\
\hline DIC-4 & 9.93 & 12.12 & 166.74 & 188.79 \\
\hline DIC-5 & 10.05 & 11.93 & 156.86 & 178.84 \\
\hline DIC-6 & 12.68 & 13.86 & 174.37 & 200.91 \\
\hline DIC-7 & 8.87 & 12.4 & 175.62 & 196.9 \\
\hline DIC-8 & 10.96 & 14.22 & 201.29 & 226.46 \\
\hline DIC-9 & 9.12 & 11.95 & 162.08 & 183.15 \\
\hline DIC-10 & 9.66 & 14.86 & 224.01 & 248.54 \\
\hline DIC-11 & 0 & 14.6 & 154 & 168.6 \\
\hline DIC-12 & 9.03 & 13.76 & 180.42 & 203.22 \\
\hline DIC-13 & 9.16 & 13.07 & 166.12 & 188.35 \\
\hline Optimum & 9.76 & 13.13 & 165.68 & 188.58 \\
\hline$<$ RM $>$ & $12.8 \pm 3.8$ & $14.3 \pm 0.7$ & $195.4 \pm 30.5$ & $222.6 \pm 26.1$ \\
\hline$<$ DIC & $9.5 \pm 3.1$ & $13.3 \pm 1.0$ & $179.5 \pm 22.3$ & $202.4 \pm 24.3$ \\
\hline
\end{tabular}

$587<$ RM>: Average of Raw Material samples

$588<$ DIC $>$ : Average of DIC treatments

589 


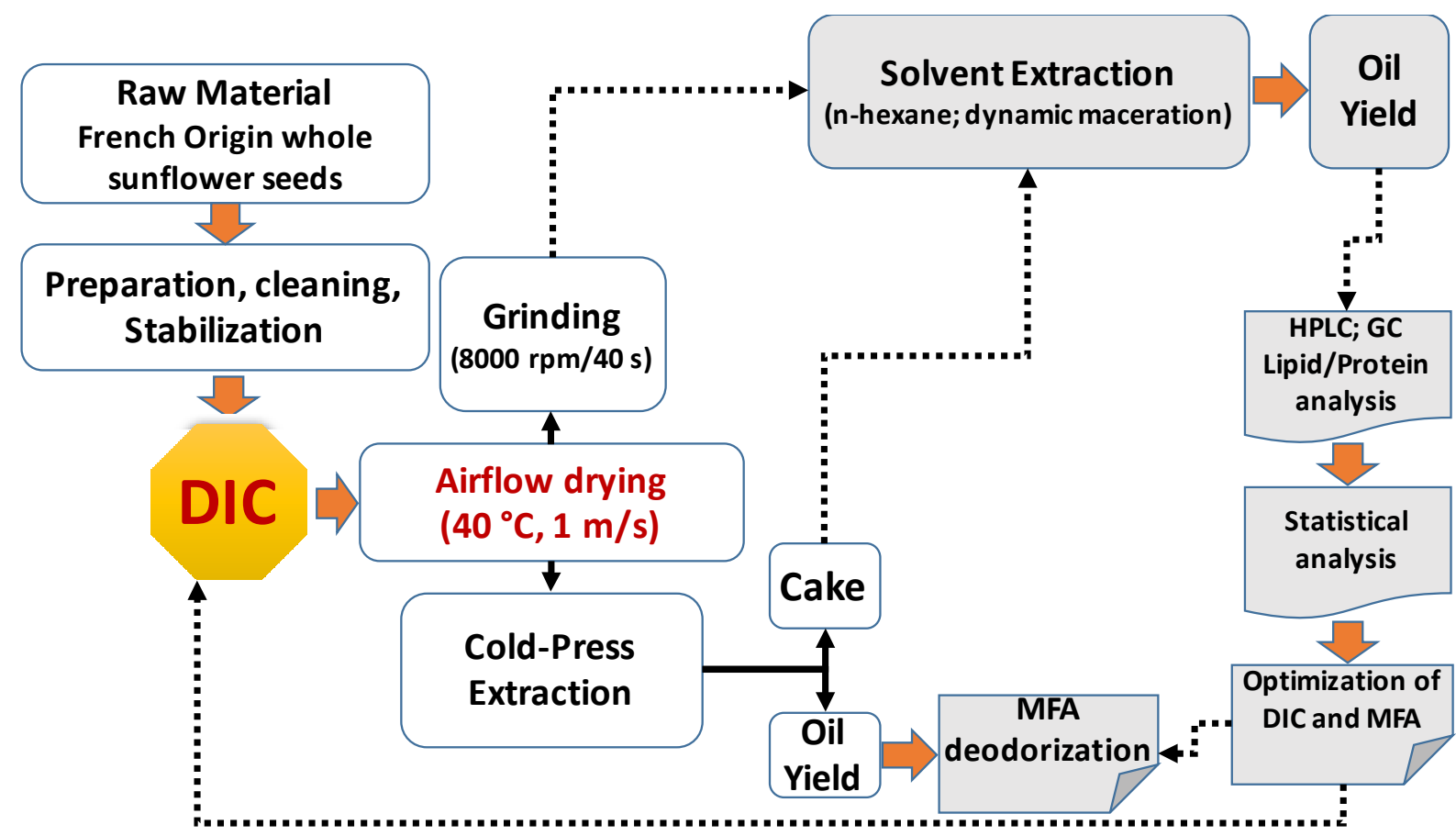




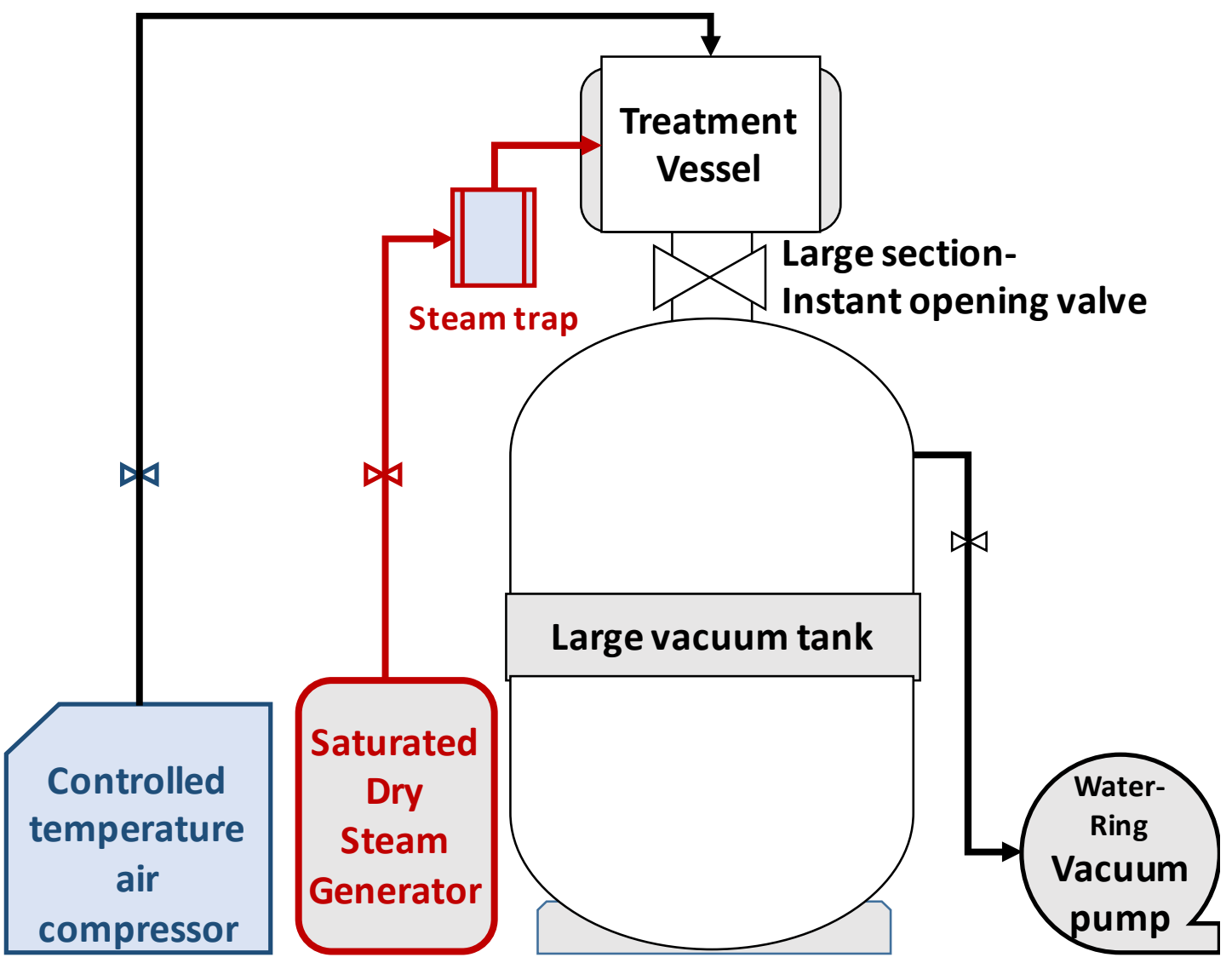

594

Figure 2. Instant controlled pressure-drop (DIC) laboratory-scale unit. 

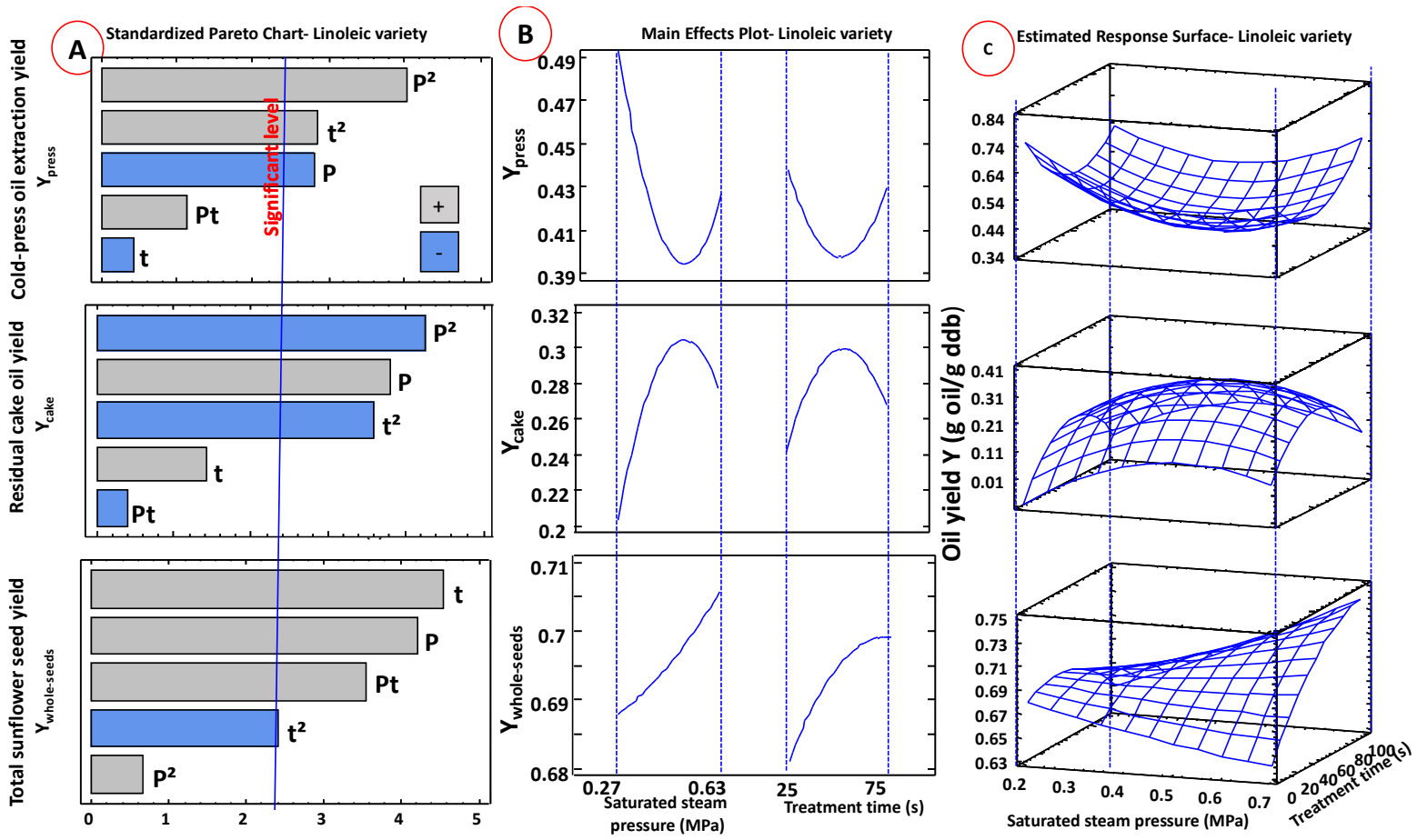

Figure 3. Effect of Instant Controlled Pressure-Drop DIC parameters on oil yields by cold-press extraction, cake oil concentration and whole oil concentration of differently DIC-textured sunflower seeds: A) Standardized Pareto Chart; B) Separated direct effects and C) Estimated response area. 
Sunflower cake - linoleic variety

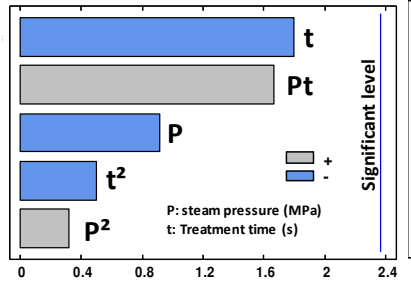

Whole seed - oleic variety

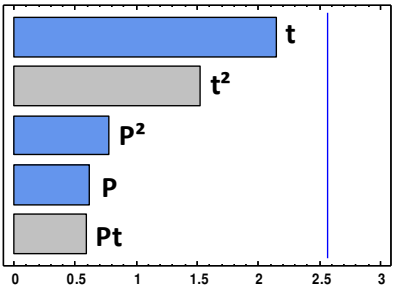

Sunflower cake - oleic variety

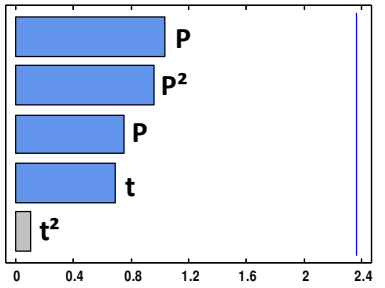

Figure 4. Standardized Pareto charts of Instant Controlled Pressure-Drop DIC pretreatment for protein content of the sunflower whole seeds and cake for linoleic and oleic varieties versus DIC processing parameters $P$ 


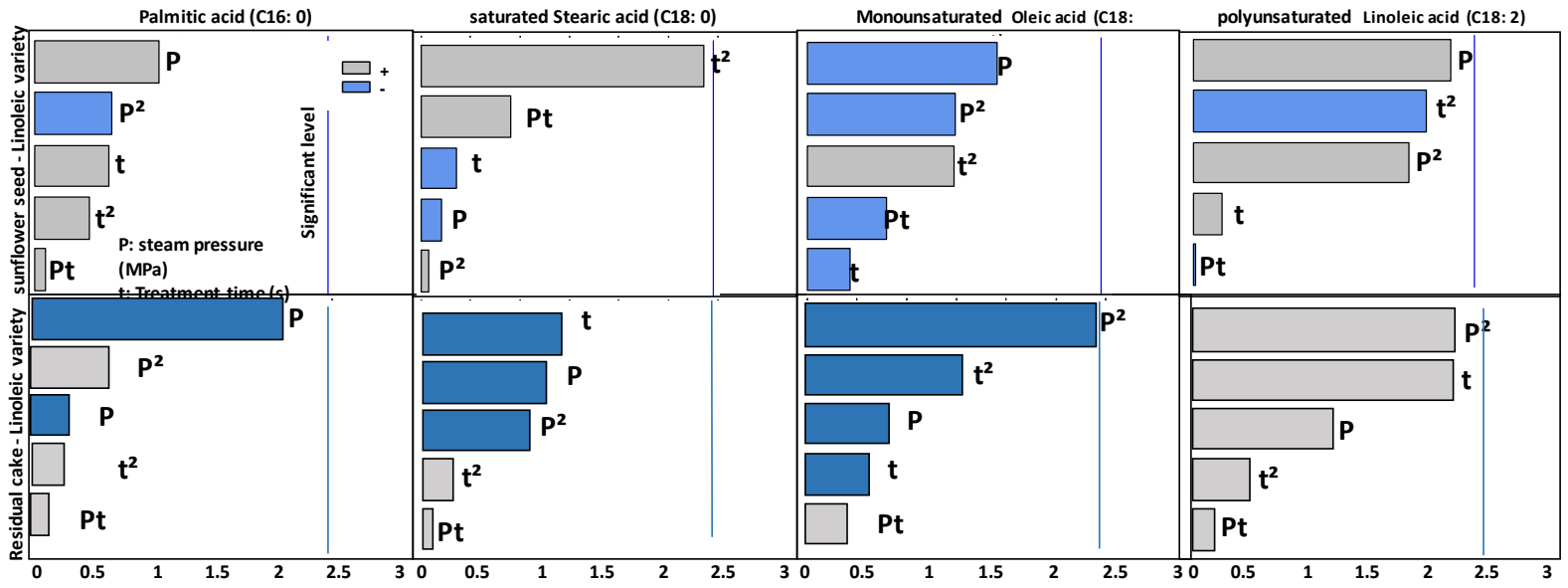

Figure 5. Standardized Pareto Charts of DoE of Instant Controlled Pressure-Drop DIC for fatty acid amounts of 608 sunflower whole seeds and cakes for linoleic varieties versus DIC processing parameters $P$ (saturated dry steam) 609 and $t$ (processing time). 
Tocopherol content of seed sunflower $(\mu \mathrm{g} / \mathrm{mg} \mathrm{db})$

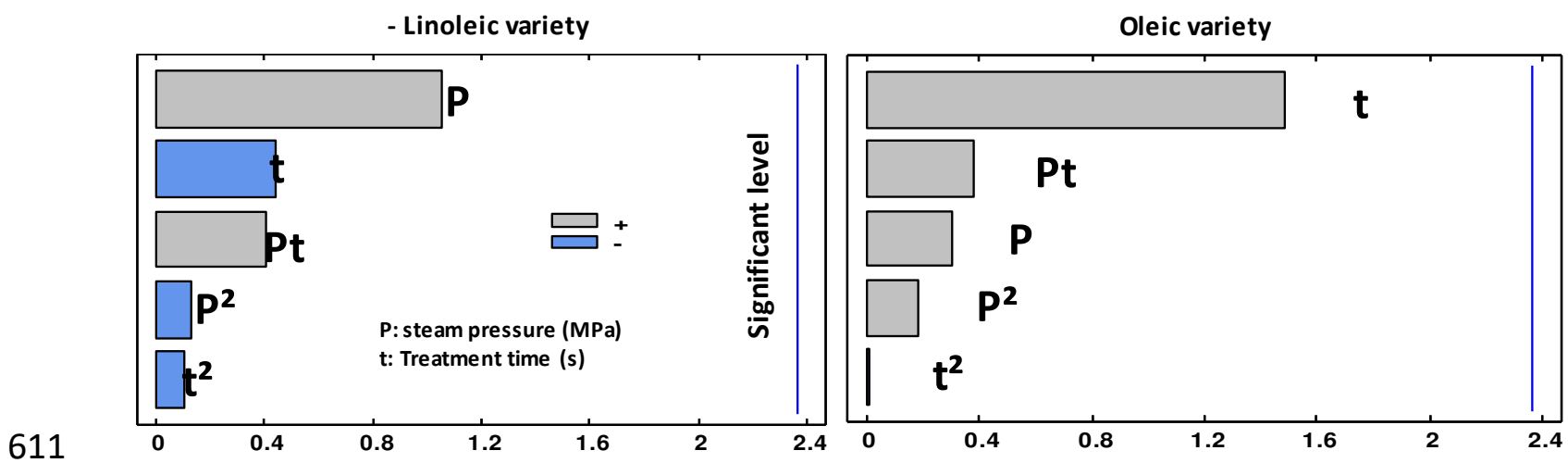

612 Figure 6. Standardized Pareto Charts for Tocopherol contents of whole sunflower seeds for linoleic and oleic 613 variety versus Instant Controlled Pressure-Drop DIC processing parameters $P$ (saturated dry steam) and $t$ 614 (processing time). 